\title{
Correction to: Direct Parallel and Hybrid Power Control Scheme of a Low-Power PV and Piezoelectric Energy Harvesting Module
}

\section{Dong-Hee Lee ${ }^{1}$ (D)}

Published online: 26 May 2021

(c) The Korean Institute of Electrical Engineers 2021

\section{Correction to: \\ Journal of Electrical Engineering \& Technology \\ https://doi.org/10.1007/s42835-021-00722-8}

Due to an unfortunate oversight the wrong Figure 10 has been included in the article. The correct figure is:

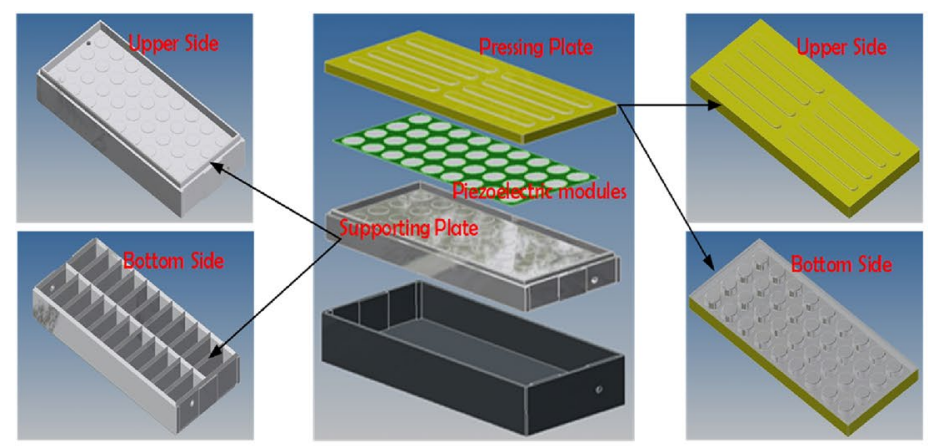

(a) Top-view of the piezoelectric module

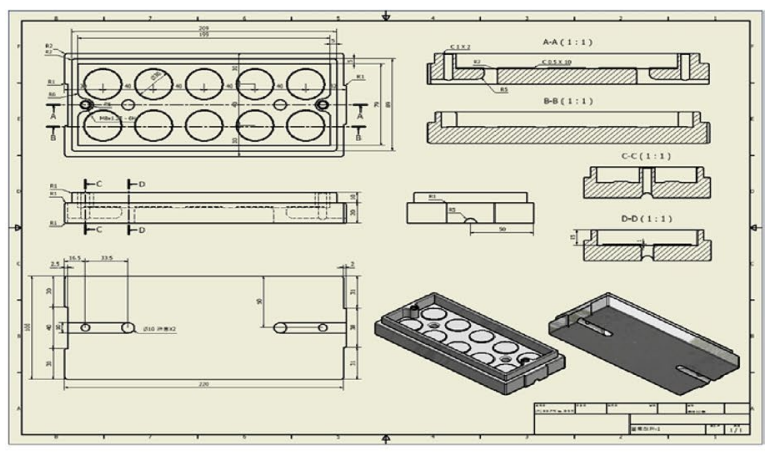

(b) Total dimension of one module

Fig. 10 Experimental confgurations

Publisher's Note Springer Nature remains neutral with regard to jurisdictional claims in published maps and institutional affiliations.

The original article can be found online at https://doi.org/10.1007/ s42835-021-00722-8.

Dong-Hee Lee

leedh@ks.ac.kr

1 Department of Mechatronics Engineering, Kyungsung

University, Busan, Republic of Korea 